\title{
Value creation and the development of knowledge-intensive service activities in Romania's travel agencies
}

\author{
Luciana- Floriana HOLOSTENCU \\ The Bucharest University of Economic Studies, Bucharest, Romania \\ luciana.holostencu@yahoo.ro
}

PICBE $\mid 854$

\begin{abstract}
This paper aims at analyzing key information regarding the value creation resulted from providing tourism services by Romanian traditional and online travel agencies in relation to the development of knowledge-intensive service activities as part of their internal operations and the usage of outsourced services. Knowledge-intensive service activities and the field of knowledge-intensive business services have gained great importance in the economy of emerging countries such as Romania. Moreover, the impact of these specialised services and activities in tourism have not been subject to many thorough domestic or worldwide researches. As a result, the study will bring a new perspective regarding the implications of innovation and investments in technology, human resources and specialized knowledge in order to develop a new form of value creation, increased customer's confidence and high profitability for the company. In order to achieve the indicated objectives, both the theoretical and empirical studies are used. The empirical study consists in collecting secondary data such as professional reviews and dedicated studies and reports from conferences and demonstrations on the subject. Also, the conducted analysis gathers mainly quantitative but also qualitative data, by applying a particularized survey and a brief interview. The results illustrate an integrative framework of the importance gained by knowledge intensive services in the process of value-creation in a tourism agency and also the key aspects regarding the new adapted form of tourism products through dynamic packaging. This study does not only capture and details the main aspects regarding the importance of knowledge-intensive service activities in the development of tourism companies, but also highlights the main features regarding customer's satisfaction through the concept of perceived value-in-use (PVI) and the new successful products created and provided to a complete new generation of clientele.
\end{abstract}

Keywords: Knowledge-intensive service activities (KISA), Knowledge-intensive business services (KIBS), Value creation, Travel Agency, Online Travel Agency (OTA)

\section{Introduction}

Still considered a transition country (Anil, Tatoglu \& Ozkasap, 2014) Romania provides an intriguing survey setting regarding its socio-economical path (Meyer \& Peng, 2005) especially since the integration into the European Union (EU). Since its emerging-country profile has started to get into shape (Brenchley, 2018), the transition of Romania could be interpreted as unique due to its fundamental switch from command economy (Grossman, 1990) to Smith's market economy. In 2017 Romania became the fastest-growing country in Europe, with the best rate of growth since 2008, based mainly on consumerism (Brenchley, 2018). Hence, Romania's population started to focus more on purchasing both goods and services, especially tourism services.

As innovation and full access to internet and functional applications has transformed the way we live and organize the main activities of our lives (as programming a holiday), our perception regarding activities like purchasing a tourism package has suffered significant alterations (Ma, Buhalis \& Song, 2003). Nowadays customers have the tendency to collect a 
great amount of information, but also they prefer to fully plan their holiday by the means of internet's valuable benefits. Therefore, customers may represent a relevant source of knowledge for tourism companies (Hall \& Williams, 2008; Poon, 1993). Also, we should take into consideration the interaction between a travel agency and the final user, because it could be a interesting opportunity for the knowledge development of the company (Sørensen \& Jensen, 2015) and its process of value creation.

PICBE | 855

In tourism, the activity of knowledge creation represents a particular process where value is generated up to a point where the process languishes or it needs to be outsourced to a specialised company where knowledge represents the main input and output, known as a knowledge-intensive business service (KIBS) (Miles, 2003). The knowledge exchange between the specialised company and the travel agency is also considered a process of value co-creation (Hipp, Gallego \& Rubalcaba, 2013). What about the information exchange between the travel agency's knowledge-based departments? At what extent does a travel agency uses its internal specialised departments in the process of innovation? Does the company's capability to use and produce knowledge and innovation influence the value offering (VO)?

This analysis focuses on the position of knowledge intensive service activities (KISA) in the Romanian tourism industry, mainly regarding the activity of traditional and online travel agencies (only tour operators). Moreover, the study will offer the possibility to gather information about innovation and other related. This is particularly relevant since, in the present knowledge economy, innovative activities represent the core of economic growth, competitiveness and value creation.

\section{Literature review}

According to many scholars, the process of innovation represents one of the fundamental assets for either travel companies or companies where the main activity consists in providing knowledge-intensive services (KIS) (Den Hertog, Gallouj, \& Segers, 2011).

Regarding a service product, in this case a travel package, the innovation concept has expanded its meaning by integrating not only the original product discovery but also new production methods, new organisational forms and marketing activities (Oslo Manual, 2005; Eurostat 2018). It has become clear that knowledge and all the changing processes characterise innovative companies and influence their competitive accomplishments and prosperity (Martinez-Fernandez et al., 2005).

A complex body of literature contributes to our understanding of the core characteristics of knowledge-intensive service activities (KISA), particularly: their information-based nature and their association to Information and Communication Technologies field (ICT) (Consoli \& Elche-Hortelano, 2010); flexibility of services thanks to existing interactions between suppliers and consumers; the role of human capital and the development of specific skills (Miles, 2005; Tether, 2003; Drejer, 2004).

The concept of KIBS was originally created by Miles et al. (1995) in relation to companies that perform as a main business the creation, accumulation and dissemination of knowledge. Furthermore, Hertog (2001) argued that KIBS function either as a facilitator, carrier or source of innovation. Through their interdependent relationship with client firms, KIBS become co-producers of innovation.

According to NACE classification (Eurostat, 2018), a wide range of activities are 
included in the knowledge intensive activities (KIA) as: consultancy services, legal, accounting services, recruitment and training activities, IT, marketing, research and development activities (R\&D) etc. What if a single service company, as a travel agency (tour operator), could incorporate a consistent part of those activities in different internal specialized departments and those departments will exchange knowledge in a process of innovation and value creation? As so, knowledge could be also accessed, adapted, processed and transformed into innovative products, processes and organizational forms, apart from external providers (KIBS, RTOs, consumers or competitors from a similar or a different service sector), on a internal basis, if the company has at its disposal all the necessary means (Martinez-Fernandez et al., 2005).

Martinez-Fernandez et al. (2005) went on a further investigation regarding the use of KISA and knowledge exchange of Australia's tourism industry and their results suggested that an is interesting phenomena is how firms are trying to innovate and mix external knowledge with their own specialized expertise. Adhering to the author's opinion regarding the existence of innovation and knowledge exchange inside a tourism company, it would be interesting to find out, if innovation could have a positive impact on the processes of value creation.

According to O'Cass and Sok (2012) the company's innovation capabilities have a positive effect on the firm's value offering (VO), onward the VO has a positive impact on the customer perceived value-in use (PVI), and PVI has a benefic relationship with the firm's performance. While the value creation process is a extremely debated subject with little consensus on what it represents from the company's perspective (Sirmon, Hitt \& Ireland, 2007) or from costumer's perspective (Ulaga \& Eggert, 2006; Priem, 2007), Bowman and Ambrosini (2000) suggest that value creation is a multi-stage process consisting in different users of value at different phases of the process. Therefore, an integrative perspective of both streams may represent a further step in the value creation literature. As an addition to this concept, O'Cass and Ngo (2010) argue that value creation is a three-stage process by which the company creates use value (value offering) as a proposal, while the final customers contribute to the creation of perceived value-in use (PVI), and the business customers realize exchange value, known as customer-based performance (CBP), at the point of exchange via B2B interaction. These three stages of value creation have the capacity to support and increase the firm competitiveness due to the ability of understanding what customers are looking for (O'Cass \& Ngo, 2010) and to create that specific value for their needs (e.g., Sirmon et al., 2007).

In order to focus on the development and value-creation of a travel agency (touroperator), it is important to note that innovations introduced by such a firm may represent an important part of knowledge-intensive service activities. Regarding the activity of a travel agency, knowledge becomes an essential step in order to meet customers' needs, especially emotional knowledge (Bratianu \& Orzea, 2013). The specialized services provided consist in the process of assisting and supporting a potential buyer for purchasing a travel package. Consequently, in order to strengthen their position in the distribution chain, travel agencies focused on their advice-giving capacity, maybe one of most reliable proofs of knowledgeintensive activity and specific value creation (Bennet, 1993). Moreover, not only that travel agencies invest in human resources knowledge, but they perform the activity of consulting which, according to Strambach (2008), characterizes a knowledge-intensive service activity. 
Researches have also indicated that the service encounters can establish a crucial source of knowledge regarding users (Toivonen \& Tuominen, 2009) and represent a great opportunity to superior value creation (Liao \& Chuang, 2004). What about an online service encounter between an online travel agency and a customer who is interested in purchasing a travel package via internet? OTAs appeared as a reaction to the lack of variety of products provided by traditional travel agencies (Ayazlar, 2014) as a concept of e-commerce platform where customers can easily access and purchase their favorite products from any virtual place and whenever they wish (Rose, 2004). Are OTAs travel agencies or tech companies? Probably, they are situated in a middle sector such as their potential of creating value through KISA. Maybe the concept of dynamic packaging (Cardoso, 2004) introduced by OTAs and nowadays used by many traditional tour-operators could be the proof of the substantial innovations in the niche? It is hard to tell yet, and further in-depth research should be done.

Building on the work of Martinez-Fernandez et al., 2005 and O'Cass and Sok (2012) this study examines the existence of innovation in Romania's tour operators (traditional an OTA's) through knowledge intensive service activities (KISA), the importance of knowledge exchange between companies (B2B), companies and consumers and mostly, at a meso-level, the one between the travel agency's departments. The analysis of innovation will consider also the process of value creation, mainly VO, and if indeed innovation is connected to value creation and the increased company performance. Even so, it is important to always have in mind the fact that once the travel agency creates and delivers its VO, it is the customer who will determine the real value-in-use as a final arbiter (Bowman \& Ambrosini, 2000).

\section{Methodology}

This niche of Romanian tourism industry was selected due to its increasing relevance to the national economy. It is also considered yet a complex industry, with inputs from many other industries that have not been studied in depth in relation to innovation as part of KISA literature. The analysis focuses mainly on quantitative techniques of data collection and analysis but also includes a brief qualitative analysis (interview) that, we hope, will contribute to a better understanding on how the companies access, handle and integrate different sources of knowledge to build up their innovation effectiveness with a positive relation to value creation. The survey conducted through a structured questionnaire involved simple statistical analysis of the responses gathered from the participants. The main questions of the survey regard: the use of innovation and KISA-related services; the main providers and their significance as inputs for KISA; the formal or informal relation between travel agencies or their relationship to the government institutions and the role of KISA in the company's innovation processes. As the study aims at analyzing especially the internal but also the external knowledge exchange in a tour-operator's activity, a sample of 23 companies which correspond to the targeted profile were contacted. The survey was open for two weeks. A total of 9 out of 23 responses were collected and submitted and the profile of the companies was the following: 6 traditional tour-operators (one corporate agency) and 3 online travel agencies (OTA).

\section{Results and discussions}

\section{Innovation as part of KISA-related services and the knowledge exchange}


According to the survey travel agencies are really innovative in terms of implementing new products and organisational changes. Eight out 9 firms (89\%) were involved in changes regarding new products and 7 of them considered that organizational innovation played an importan role regarding their performance. Also, 56\% believed new processes or other operational changes had a postivie impact regarding innovation and only 4 companies considered marketing innovation important. It is interesting to know that 3 out of the 4 mentioned were OTA's who consider themeselves part travel agencies and part tech companies.

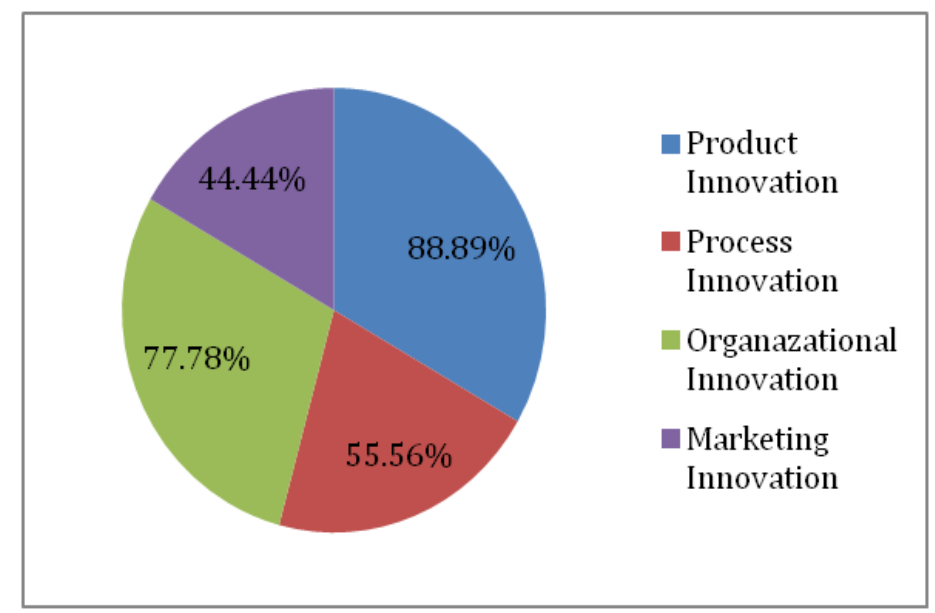

Figure 1. Types of innovation in a travel agency

\section{KISA-related services inputs}

Source: Authors' own research

Regarding the use of inputs to KISA for the development of the innovation types mentioned before, we decided to perform a questionnaire regarding: industry development advice, business planning advice, marketing and promotion, $\mathrm{R} \& \mathrm{D}$ as market research and product development, accounting and finances, training, recruitment, accreditation, IT and Ecommerce.

As Figure 2 shows, $44 \%$ of firms consider the industry development of highimportance, while $56 \%$ think it has a medium importance. Identical results regard the process of recruitment. With respect to the activity of business planning advice, 56\% feel that it is of high importance, while $44 \%$ of medium. Moreover, the same interest was manifested regarding the IT activities, where 3 out of the 5 companies who rated this activity as of highinterest were the OTAs. The use of IT services as highly and of medium importance might be a clue regarding the integration of ICT into usual business management systems (Main, 2002) or in using it at a higher technological level as do the nowadays OTA's (Buhalis, 2003). The situation regarding marketing and promotion is almost similar where the 3 OTAs out of the 4 respondents considered the activity highly important, while the 5 others considered it of medium importance. $R \& D$ faces a distressing situation due to the lack or little of interest manifested by the companies. It is a single situation where only 3 of them considered it of highly important, while other 3 opted for medium and the last 3 for a low level of importance. The same situation can be found regarding e-commerce services where only the 3 OTA's considered it highly important. On the other hand, accounting and finance is perceived as a border KISA, where $67 \%$ of the respondents consider it of medium importance and only 3 rated it as highly important. The top position is held by the interest manifested in the 
accreditation and training process where 9 out of the 9 companies rated them as highly important.

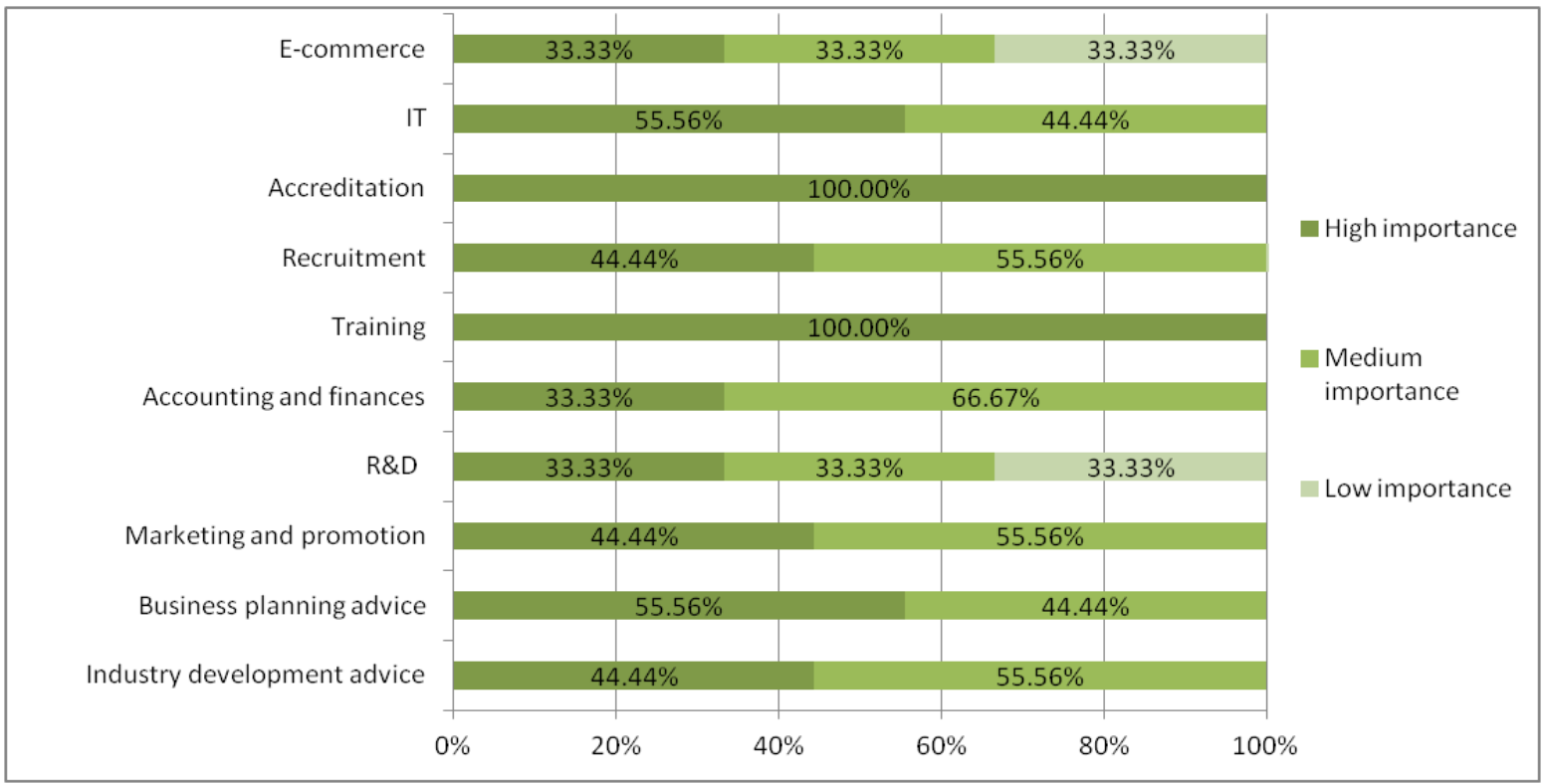

PICBE | 859

Figure 2. Importance of KISA inputs

Source: Authors' own research

Each company has its own approach regarding the process of collecting, generating, exchanging and integrating knowledge into innovation. KISA can be different in every case and the activities undertaken by travel agencies might be a ground to a different situation based on the consumers PVI. Regarding the industry development, 44\% of the respondents preferred internalization while $56 \%$ opted for the mix. In a slightly different situation is found business planning advice with 67\% internalization and 33\% mix, while only $22 \%$ opted for internalized marketing and promotion, $11 \%$ externalized services and the remaining $67 \%$ opted for the mix. The $\mathrm{R} \& \mathrm{D}$ process is non-existent on an internal level but is developed as a externalized service (67\%). Accounting and finances are internalized (67\%) and a mix of 33\%. Training is considered an important part of the internal activity (57\%) while only $22 \%$ of the respondents externalize the services. Recruitment is almost $80 \%$ perceived as an internal activity and only $22 \%$ prefer the mix. In the respondents opinion, accreditation is mostly a internalized but also a mix of activities, while IT is preferred as an externalized one, or at least a mix of knowledge exchange between a KIBS and the travel agency (33\%). Although IT is better in an external knowledge-exchange the process of implementation a e-commerce platform is preferred at an internal level (44\%) or at least a collaboration (33\%). Figure 4 displays the most significant sources of KISA inputs. While in-house and KIBS were the most common sources of expertise, we could also take into consideration that most of the external knowledge has its main sources at a local or national level. 


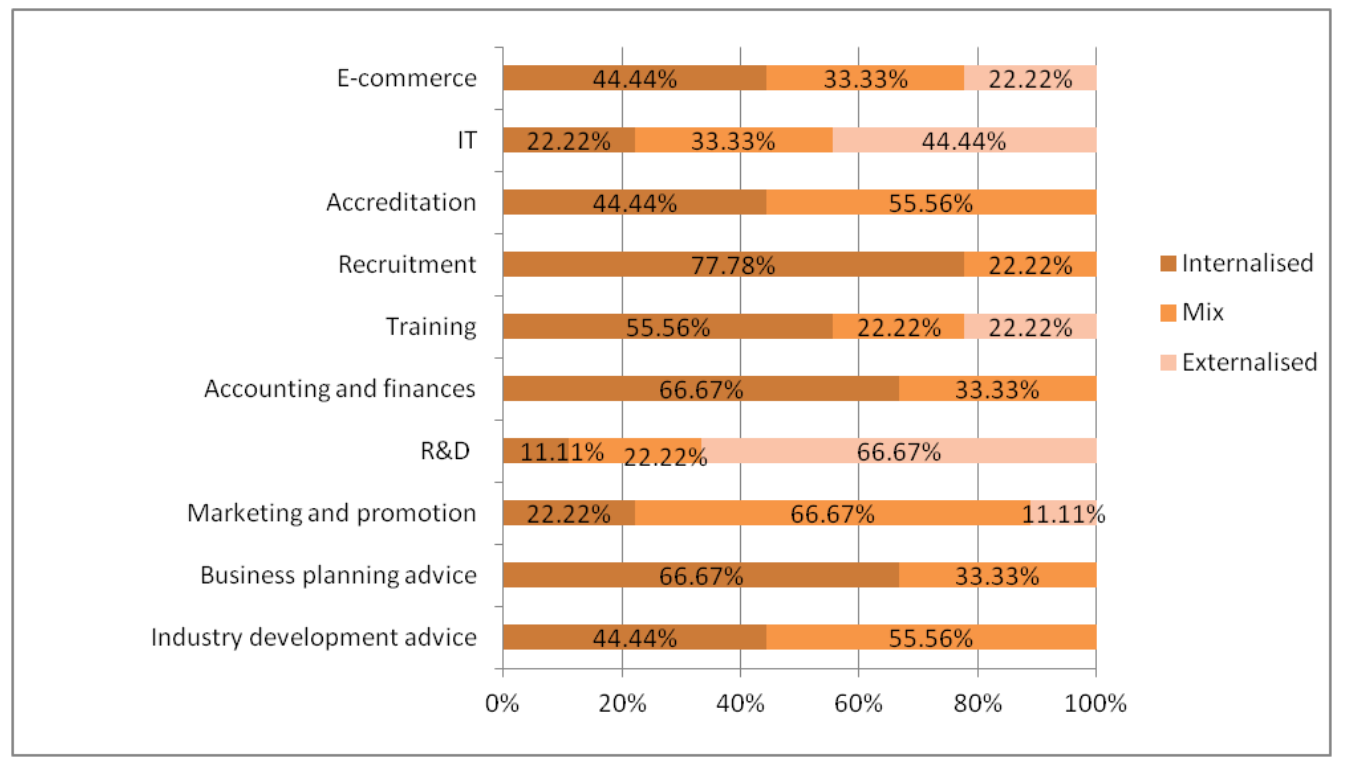

Figure 3. Sources of KISA-related services inputs

PICBE | 860

Source: Authors' own research

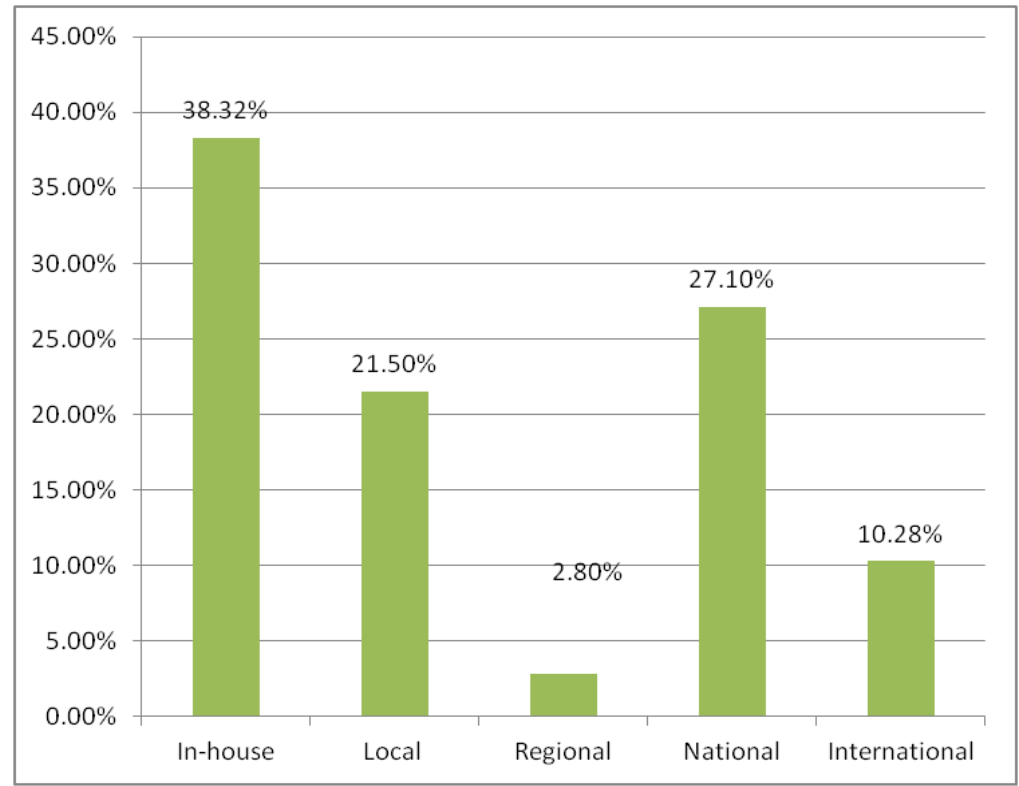

Figure 4. Location of KISA-related providers

Collaboration with partners in the process of innovation

Source: Authors' own research

Respondents were requested to articulate their collaboration to providers of knowledge or even partners or customers and to clarify the importance of engagement in the process of innovation. The analysis showed that all travel agencies had a highly-rated and formal collaboration with customers, KIBS and other group companies. On the other side the relation with their competitors was perceived as highly-rated but mostly on informal grounds. Unfortunately, the collaboration with government institutions is almost non-existent, probably due to the lack of interest manifested by the state. A medium-rated informal collaboration with the universities and colleges was profiled, which might mean the interest 
manifested by both parties in the knowledge-exchange process. Collaboration between firms of the same group was equally considered of high, medium and low importance.

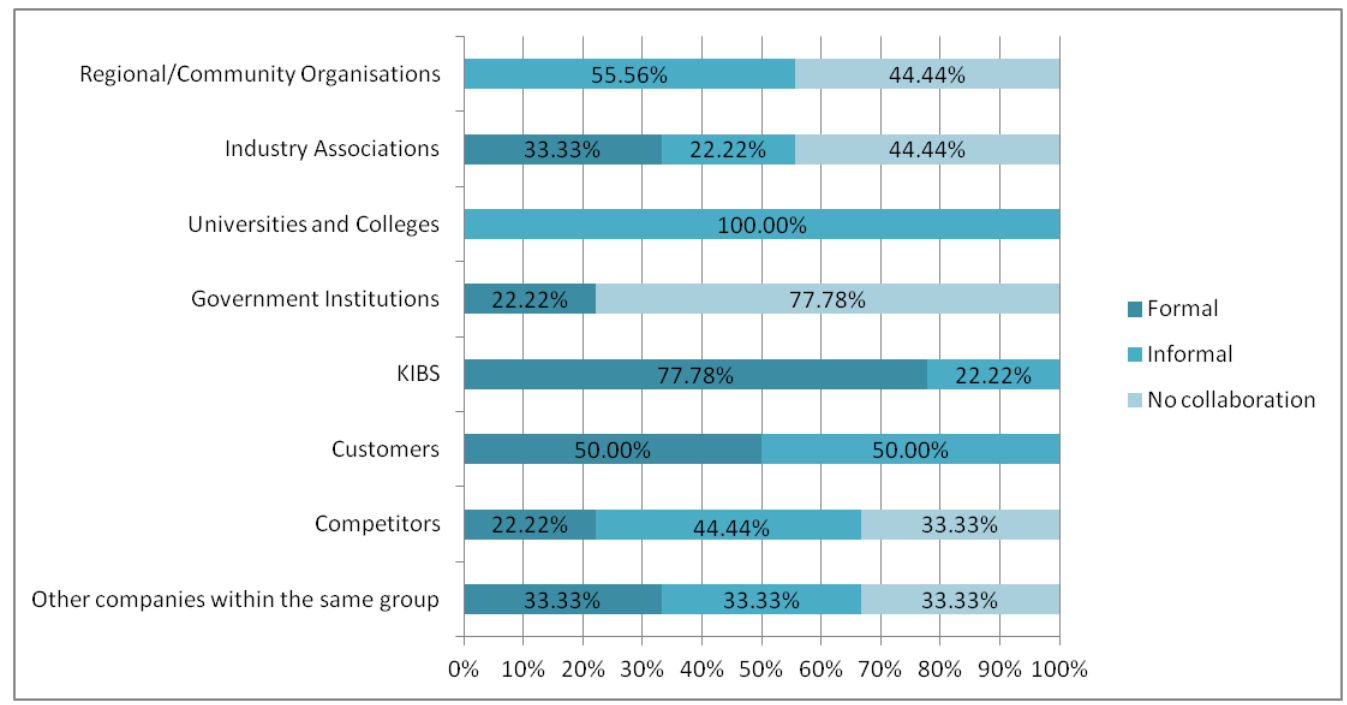

Figure 5. Types of collaboration

Source: Authors' own research

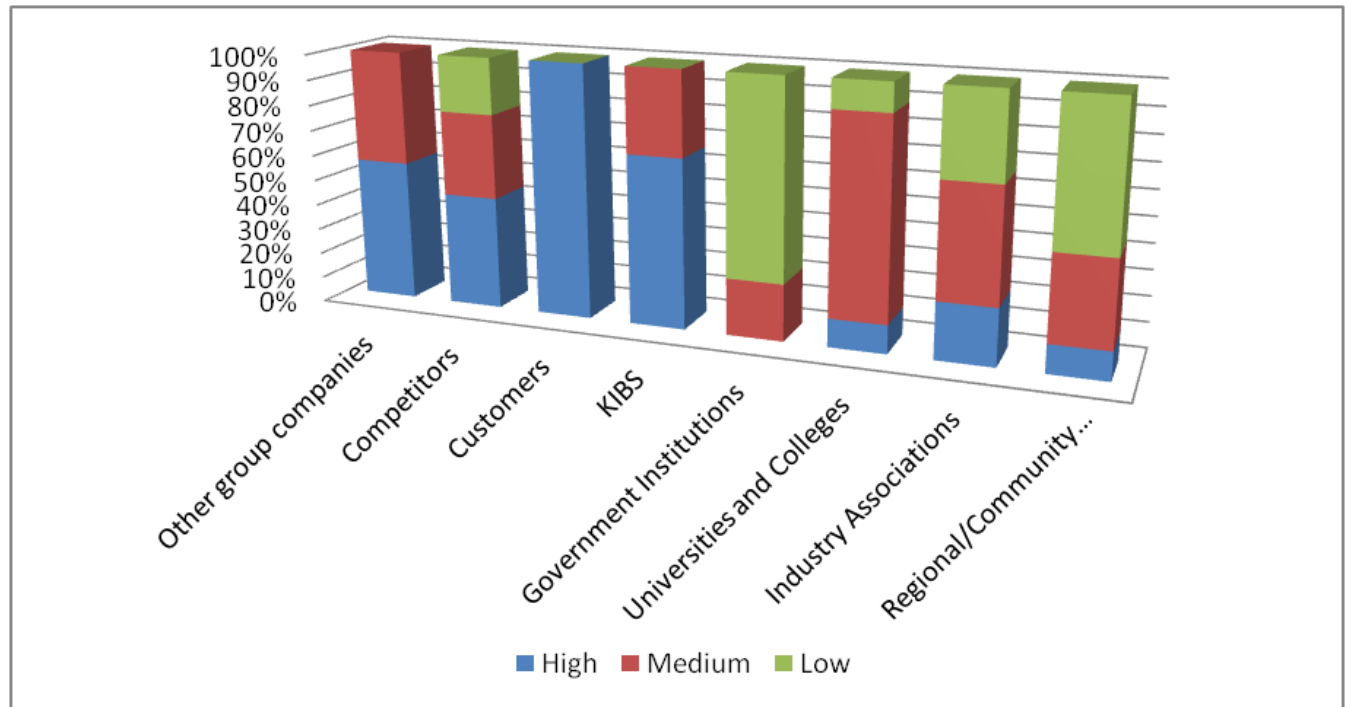

Figure 6. Importance of the colaboration

Source: Authors' own research

\section{Grounds for choosing outsourced inputs to KISA}

According to the analysis all the firms, on an exclusive or mix of choices, outsourced some parts of their services to providers. The main KISA-related services preferred for outsourcing or mixing with the firms' input were IT, E-commerce and marketing followed closely by the industry development advice. Each company has selected those providers for different reasons. The main grounds of decision making were personal and business networks, along with the reputation that some external providers have got through recommendation. Moreover, travel agencies are trying to keep up-to-date with the latest innovations in the 
areas where they need particular services. Also, market research represent a reliable tool of decision making regarding the future partners in a process of knowledge-exchange and value creation. Furthermore, as Figure 8 indicates the main reason for choosing outsourced services was the lack of in-house expertise and companies' desire to level up the internal efficiency.

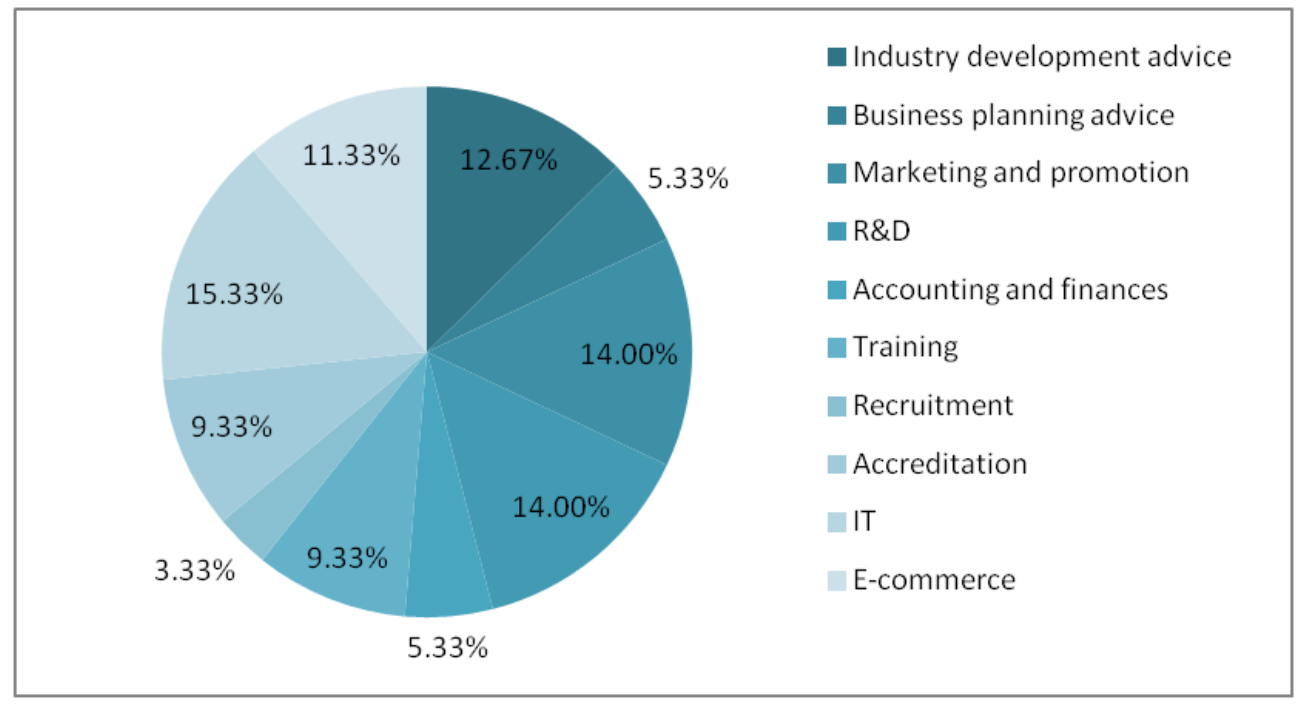

PICBE | 862

Figure 7. Main sources of external KISA inputs

Source: Authors' own research

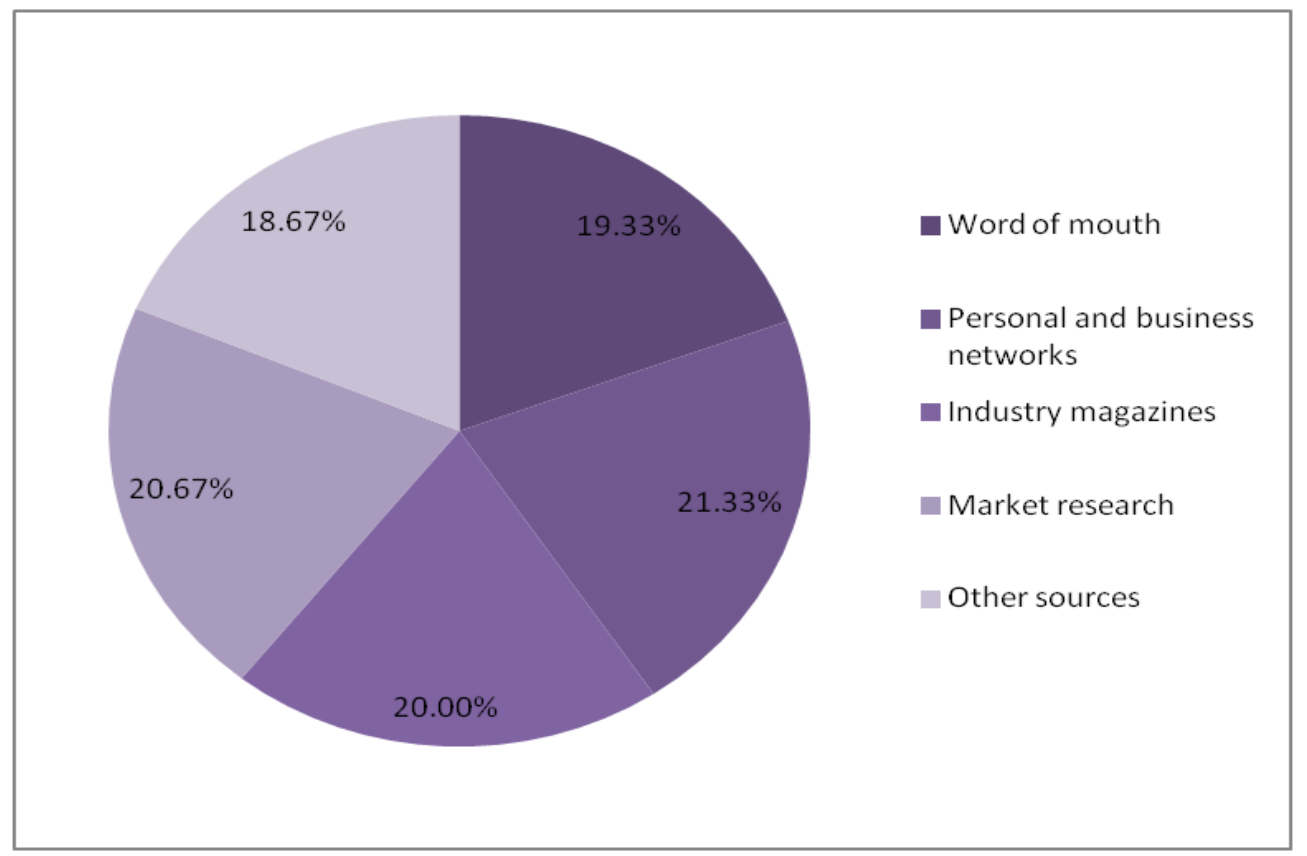

Figure 8. Grounds of decision-making

Source: Authors' own research 


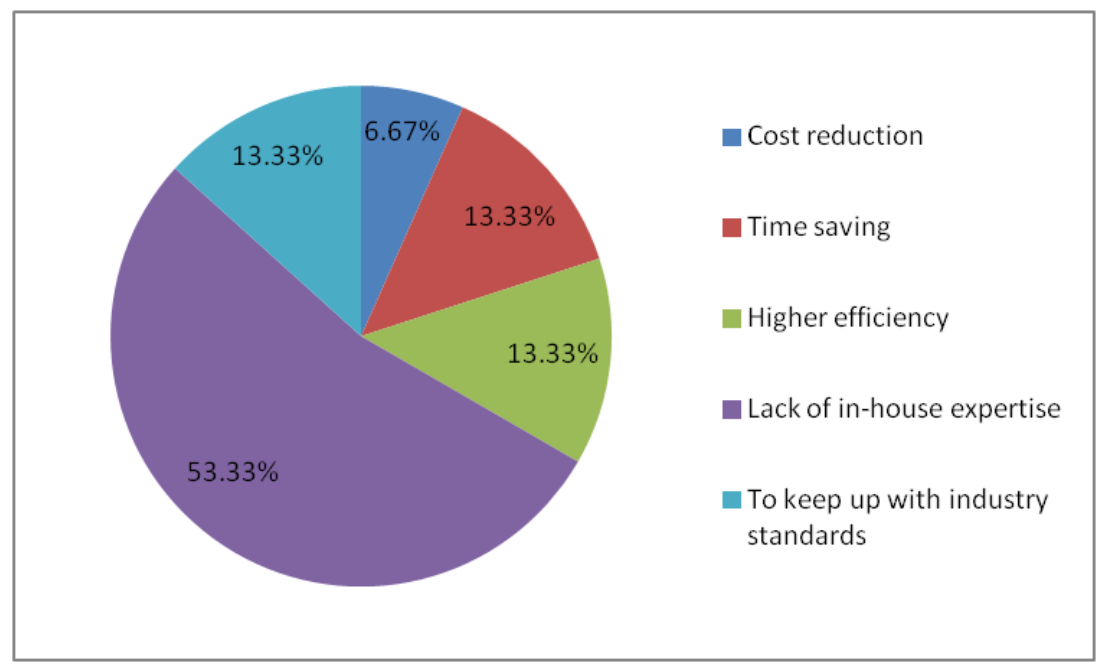

PICBE | 863

Figure 9. Reasons for outsourcing KISA inputs

Source: Authors' own research

\section{Grounds for choosing in-house inputs to KISA-related services}

KISA can also be implemented internally, either by knowledge-oriented specialized departments, or throughout the interaction of those departments across the firm. The results showed that internal provision of KISA is mainly proffered due to the improvement of operations and efficiency in the company and later on, due to lower cost for the process of innovation.

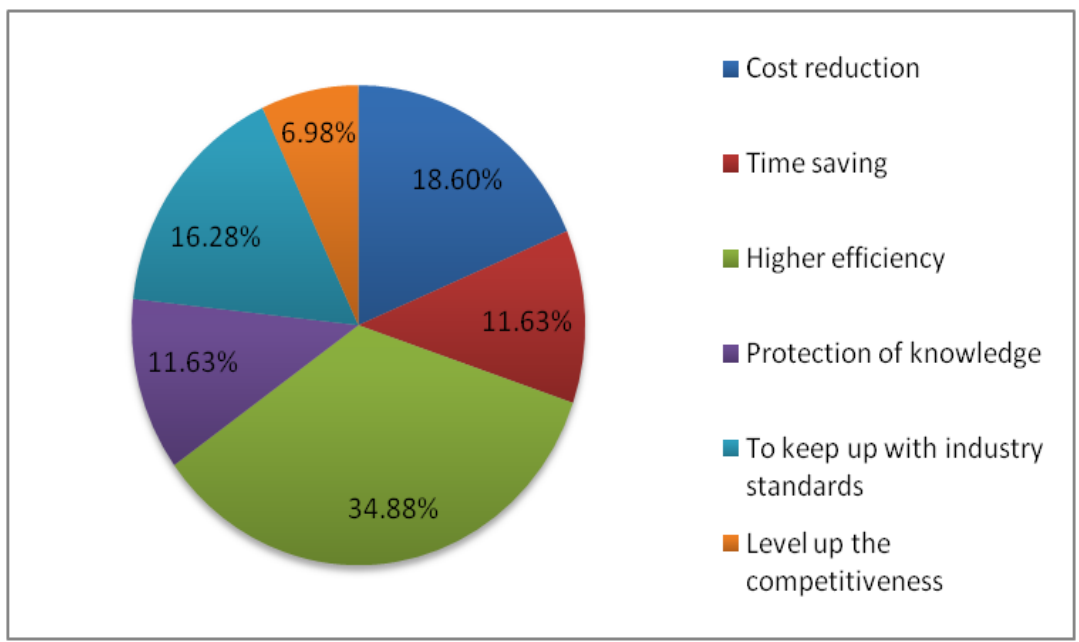

Figure 10. Reasons for internalisation of KISA inputs

Source: Authors' own research

As a subject of a further study should be the fact that 2 out of 3 OTAs opted for the internalization of the IT and E-commerce activities, two mainly KISA activities that were fully integrated in a travel agency. Also, the 3 other firms that opted for a mix of provisions have proved their ability to innovate with the purpose of a higher efficiency. Could be this efficiency connected to the process of value creation, specifically, value offering taking into account that over the last three years, all companies have experienced substantial financial 
increases? Given the quite small sample of respondents we could only presume it might be real possibility to connect innovation, value offering and higher performances as O'Cass and Sok (2012) stated before.

\section{Business life cycle and KISA vs. product life cycle and KISA}

As to the frequency of using KISA-related services in relation to a company business lifecycle, PICBE | 864 adhering to Jameson (2000) motivation, a starting company is not able to use specialized services due to the lack of resources, exceptions make the OTAs who started their activity based on a consistent investment fund. The frequency of using the services grew considerably in correspondence to the gradually development of the company, so as the company grew, it used more knowledge-intensive activities. However, it is interesting to note that in Romania's travel agencies R\&D are only used at the expansion stage of the business.

Table 1. The frequency of using KISA - related services and the firm's business life

Source: Authors' own research

\begin{tabular}{|l|l|l|l|l|}
\hline KISA - related services & $\begin{array}{l}\text { Starting } \\
\text { business }\end{array}$ & $\begin{array}{l}\text { New } \\
\text { business }\end{array}$ & $\begin{array}{l}\text { Mature } \\
\text { business }\end{array}$ & $\begin{array}{l}\text { Expansion } \\
\text { Business }\end{array}$ \\
\hline Industry development advice & & & & \\
\hline Business planning advice & & & & \\
\hline Marketing and promotion & & & & \\
\hline R\&D & & & & \\
\hline Accounting and finances & & & & \\
\hline Training & & & & \\
\hline Recruitment & & & & \\
\hline Accreditation & & & & \\
\hline IT & & & & \\
\hline E-commerce & & & & \\
\hline
\end{tabular}

Table 2. The product life cycle and use of KISA

\begin{tabular}{|l|l|l|l|}
\hline KISA - related services & Creation & Maturing & Standardization \\
\hline Industry development advice & & & \\
\hline Business planning advice & & & \\
\hline Marketing and promotion & & & \\
\hline R\&D & & & \\
\hline Accounting and finances & & & \\
\hline Training & & & \\
\hline Recruitment & & & \\
\hline Accreditation & & & \\
\hline IT & & & \\
\hline E-commerce & & & \\
\hline
\end{tabular}

Source: Authors' own research

The product life cycle is constituted of three stages: creation, maturing and standardization stage. Therefore, the respondents were asked to indicate the KISA that the company counted on for each stage. The main KISA involved during the creation stage were: industry development advice, business planning advice, marketing and promotion, 
accounting and finances, recruitment and accreditation. As the table below indicates, the maturing stage involved business planning advice, R\&D, training and IT. The final stage of standardization involved again marketing and promotion, accreditation, IT and E-commerce.

\section{Challenges to innovation}

The main barriers that a tour operator faces in the innovation process with a highly risky profile was the fear of other competitors, the lack of skilled personnel, market information and appropriate finances. Despite the country economical and legal malfunction the companies are not afraid of the strict regulation or the social and economical risk, mainly because, as they stated in the interview, they are knowledge-based and put effort into creating the best packages for their tourists hence, their happy customers are the main reason of economic growth.

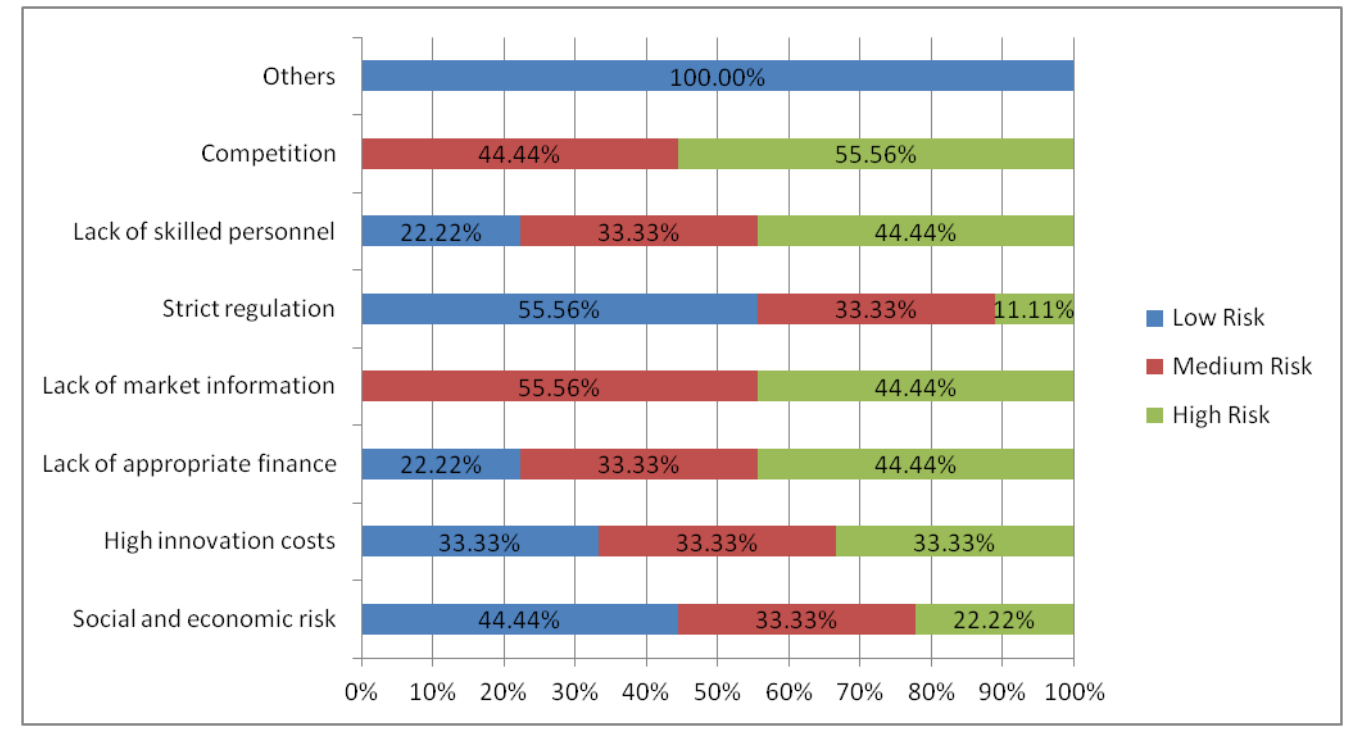

Figure 10. Barriers in innovation

\section{Managers' opinion regarding innovation and value creation}

Source: Authors 'own research

In order to shed light onto the matter we analyze, 3 out of the 9 companies accepted to participate on a brief interview: an OTA, corporate and a traditional travel agency. Their business performances on the Romanian tourism market are indisputable. The interviews were performed with members of top management. Regarding the process of innovation they were asked if innovation is important for the success of the company, and all of them agreed that both process and organizational innovation contribute to the company's development and success. OTA argued that the essential type of innovation is product innovation, taking into consideration that 9 years ago the company implemented the concept of dynamic packing. Also, the company considers itself more a tech one, rather than a travel agency. The corporate agency argued that the key to their success was process innovation and the mix innovation was the option of traditional agency. Regarding the relationship with clients, all of them agreed upon the fact that client's high level of satisfaction represents the main target and his needs are seriously taken into consideration. Two out (OTA and corporate) of the 3 companies support their long-distance relationship using technology. 
Communication is smooth and both companies, through tech tools can identify customers' needs more easily. The traditional agency, has implemented also a new online system and is trying to keep up with the latest changes, but considers that the physical interaction might still be the key to a successful value-in-use. Regarding the externalization, 2 out of 3 companies agreed upon the fact that outsourcing might be useful to the process of value creation, while the corporate agency concluded that it is benefic only for reducing costs. Regarding the relationship between public providers of KISA, especially government institutions, all firms made no comments.

\section{Conclusion}

The analysis indicated that travel agencies are really innovative in terms of implementing product and organizational changes. It might be interesting the fact that, in correlation to the managers interviews regarding the company's success based on product development and a strong relationship with customers, the idea of creating value-offering with a consistent impact on perceived value-in-use through the process of innovation and KISA, might be valid.

The survey also described various KISA considered very important for innovation and value creation. Industry development advice, marketing and promotion services, IT and Ecommerce were considered most valuable regarding innovation and knowledge-exchange. Companies preferred in-house knowledge exchange rather than outsourcing, in order to obtain a higher percentage of efficiency and cost reduction. Outsourced and mixed services were mainly useful for IT and R\&D, where companies didn't have the proper knowledge to innovate.

The analysis also discovered that travel agencies used different types of KISA at distinctive stages of their product life cycle. Operating on a dynamic and requiring niche, they needed to adapt according to the buyer-persona, who's needs are continuously changing. During the creation stage, the industry development was a barometer regarding the direction of the company, in relation to business planning advice and, of course, marketing. Planning a proper budget regarding the future activity might be an essential phase of the creation. Also, a company could not work properly without the functional recruitment and later on (maturing stage) with a specific product training.

After the product placement, the companies changed their choices of KISA, as so: a new business strategy had to be adopted, the use of IT and HR training became a must. The new improvements had to be made in relation to the process of R\&D. Finally on the last stage, companies had to get involved in the E-commerce activity and get sure that their products were recognized on the niche.

In relation to the brief interview performed on 3 types of travel agencies (OTA, corporate and traditional) our assumption regarding the process of innovation in relation to KISA and value-creation might be confirmed. The main ideas we could select were: innovation was a part of their successful path, a company will innovate taking into consideration the consumer's needs in relation to innovation and a happy consumer is has a high PVI which means a high VO.

Nevertheless, there are certain limitations to this analysis. First, we consider the number of respondents to the survey was not a statistically representative sample of the niche, so no claims can be made in regards to the representation of the whole industry. 
Second, the number of interviews and its content was very brief so it is not possible to draw conclusions, only small directions for deeper analysis. The analysis of the participating travel agencies is a starter in the process of understanding KISA's role and value creation in Romania's travel agency market.

\section{References}

Anil, I., Tatoglu, E., \& Ozkasap, G. (2014). Ownership and market entry mode choices of emerging country multinationals in a transition country: Evidence from Turkish multinationals in Romania. Journal for East European Management Studies, 19(4), 413-452.

Ayazlar, R. (2014). Dynamic Packaging Applications In Travel Agencies. Procedia - Social and Behavioral Sciences, 131,326-331.

Bennet, M.M. (1993). Information technology and travel agency: A customer service perspective. Tourism Management, 14(4), 259-266.

Bowman, C. \& Ambrosini, V. (2000). Value creation versus value capture: Towards a coherent definition of value in strategy. British Journal of Management, 11(1), 1-15.

Bratianu, C. \& Orzea, I. (2013). Emotional knowledge: The hidden part of the knowledge iceberg. In Janiunaite, B., Pundziene, A. \& Petraite, M. (Eds.). Proceedings of the $14^{\text {th }}$ European Conference on Knowledge Management (pp. 82-90), Kaunas University of Technology, Lithuania, 5-6 September 2013. Reading: Academic Conferences and Publishing International.

Brenchley, D. (2018). Booming Romania Set for Upgrade to Emerging Market, Morningstar, Retrieved from http://www.morningstar.co.uk/uk/news/168155/boomingromania-set-for-upgrade-to-emerging-market.aspx/

Buhalis, D. (2003). E-Tourism: Information Technology for Strategic Tourism Management. Englewood Cliffs, N.J.: Prentice Hall.

Cardoso, J. (2004). Issues of Dynamic Travel Packaging Using Web Process Technology, IADIS Interactional Conference e-Commerce, 357-362.

Consoli, D. \& Elche-Hortelano, D. (2010). Variety in the Knowledge base of Business Service sectors, Research Policy, 39 1303-1310.

Drejer, I. (2004). Identifying innovation in surveys of services: a Schumpeterian perspective. Research Policy, 33, 551-562.

Eurostat (2018), Concepts and Definitions, Eurostat's Concepts and Definitions Database, Retrieved from <http://www.popsci.com/popsci37b144110vgn/html>

Hall, C., \& Williams, A. (2008). Tourism and innovation. London: Rutledge.

Grossman G. (1990).Command Economy. In: Eatwell J., Milgate M., Newman P. (eds) Problems of the Planned Economy. The New Palgrave. Palgrave Macmillan, London.

Hertog, P.D. (2001). Knowledge Intensive Business Services as Co-producers of Innovation, International Journal of Innovation Management, 4(4), 491-528.

Hertog, P.D., Gallouj, F., \& Segers, J. (2011). Measuring innovation in a "low-tech" service industry: the case of the Dutch hospitality industry. The Service Industries Journal, 9(July), 1429-1449.

Hipp, C., Gallego, J., Rubalcaba, L. (2013). Shaping innovation in European knowledgeintensive business services, Springer-Verlag, Berlin Heidelberg, Berlin. 
Jameson, S.M. (2000). Recruitment and Training in Small Firms. Journal of European Industrial Training, 24(1), 43-49.

Ma, J., Buhalis, D., Song H. Y. (2003). ICTs and Internet adoption in China's tourism industry, International Journal of Information Management, 23, 451-67.

Main, H.C. (2002). The Expansion of Technology in Small and Medium Hospitality Enterprises with a Focus on New Technology, Information Technology \& Tourism, $4(3 / 4), 167-174$.

Martinez-Fernandez, M.C.; C. Soosay; V.V. Krishna; P. Toner; T. turpin; M. Bjorkli and K.N. (2005), Knowledge Intensive Service Activities in Innovation of the Tourism Industry in Australia, AEGIS Australia

Meyer, K.E., Peng, M.W. (2005). Probing theoretically into Central and Eastern Europe: Transactions, resources and institutions, Journal of International Business Studies, $36(6), 600-621$.

Miles, I. (2003). Knowledge Intensive Services' Suppliers and Clients. Report to the Ministry of Trade and Industry Finland, Studies and Reports, 15.

Miles, I., 2005. Innovation in services. In: J. Fagerberg, J., D. Mowery, D., R.R. Nelson, R.R. (Eds.), The Oxford Handbook of Innovation. Oxford University Press, Oxford.

Miles, I., Kastrinos, N., Flanagan, K., Bilderbeek, R., den Hertog, B., Huntink, W. \& Bouman, M., (1995). Knowledge intensive Business Services: Users, Carriers and Sources of Innovation. European Innovation Monitoring System (EIMS), 15, Luxembourg.

O'Cass, A. and Ngo, L. V. (2010). Examining the Firm's Value Creation Process: A Managerial Perspective of the Firm's Value Offering Strategy and Performance. British Journal of Management, 22, 646-671.

O'Cass, A., Sok, P. (2012). Exploring innovation driven value creation in B2B service firms: The roles of the manager, employees, and customers in value creation. Journal of Business Research, 66, 1074-1084.

OECD (2005), Oslo Manual. Guidelines for collection and interpreting innovation data, Retrieved from http://ec.europa.eu/eurostat/ramon/statmanuals/files/9205111E.pdf.

Poon, A. (1993). Tourism, technology and competitive strategies. Oxford: CAB International.

Priem, R. L. (2007). A consumer perspective on value creation. Academy of Management Review, 32(1), 219-235.

Rose, N. L. (2004) Selling Complex Leisure Travel Online: Focus on Dynamic Packaging Technology, Published by Travel Tech Consulting Inc. and PhoCusWright Inc. (Ed. By Lorraine Sileo and Michael Connizzaro)

Sirmon, D., Hitt, M., \& Ireland, D. (2007). Managing firm resources in dynamic environments to create value: Looking inside the black box. Academy of Management Review, 32(1), 273-292.

Sørensen, F., Jensen, J.F, (2015) Value creation and knowledge development in tourism experience encounters, Tourism Management, (46) 336-346.

Strambach, S., (2008), Knowledge-Intensive Business Services (KIBS) as drivers of multilevel knowledge dynamics, Services Technology and Management, 10, Nos. $2 / 3 / 4,152-174$

Tether, B.S., 2003. The sources and aims of innovation in services: variety between and within sectors. Economics of Innovation and New Technologies, 12, 481-505. 
Toivonen, M., \& Tuominen, T. (2009). Emergence of innovations in services. The Service Industries Journal, 29(7), 887-902.

Ulaga, W., \& Eggert, A. (2006). Value-based differentiation in business relationships: Gaining and sustaining key supplier status. Journal of Marketing, 70(1), 119-136.

PICBE | 869 